\title{
PERANCANGAN SISTEM INFORMASI AKADEMIK BERBASIS WEBSITE PADA MADRASAH TSANAWIYAH YAYASAN FISABILLILAH BEKASI
}

\author{
Nia Nuraeni \\ STMIK Nusa Mandiri Jakarta \\ JI. Kramat Raya No. 18 Jakarta Pusat, 021-31908575 \\ e-mail: nia.nne@nusamandiri.ac.id
}

\begin{abstract}
Abstraksi
Kegiatan akademik adalah proses di mana pelaksanaan kegiatan pendidikan pada kegiatan membutuhkan informasi cepat. Namun nyatanya tidak sedikit hambatan yang terjadi. $\mathrm{Hal}$ ini karena sering terjadi akumulasi data siswa dan mengakibatkan kesulitan mencari data siswa jika sewaktu-waktu data diperlukan, dibutuhkan waktu yang cukup lama dalam pembuatan laporan data siswa, pencatatan nilai akademik siswa ke dalam siswa. buku nilai akademik dan ke dalam kartu laporan dan juga membuat nilai laporan siswa akademik yang harus diserahkan kepada kepala sekolah. Hasil akhir dari penelitian ini yaitu sistem informasi berbasis web yang dapat memberikan informasi akademik lebih cepat untuk diketahui oleh orang tua siswa, sistem informasi berbasis web mencatat data siswa lebih cepat dalam penyajian laporan data siswa
\end{abstract}

Kata Kunci: Sistem Informasi Akademik, Website, MySQL and Php

\begin{abstract}
An academic activity is a process where the conduct of educational activities on the activities requires fast information. But in fact not a few obstacles that occur. This is because often the accumulation of student data and resulted in the difficulty of searching student data if at any time the data is needed, it takes quite a long time in making the report of student data, recording the academic value of students into the student academic score book and into report cards and also create report value academic students who must be submitted to the principal. The end result of this research that is a web-based information system that can provide academic information faster to be known to parents of students, web-based information system recording student data more quickly in presenting data reports students.
\end{abstract}

Keyword: Academy Information System, Website, MySQL and Php

\section{Pendahuluan}

Madrasah Tsanawiyah Yayasan Fisabillilah (MTs Yasfi) Bekasi merupakan madrasah tsanawiyah yang berstandar nasional. Sekolah ini terletak di bekasi, tepatnya Jl Raya Kp. Sawah Jatimurni Pondok Melati. Sekolah ini cukup dikenal karena bahan ajar serta staf guru yang ada disekolah tersebut memang berkualitas dan sangat berbasiskan agama, yang tentu saja membuat banyak orang tua ingin menyekolahkan anak-anak mereka disekolah ini.

Saat ini, MTs Yasfi sedang berusaha mengembangkan sistem informasi akademik yang ada disekolah tersebut. Tujuannya, agar semua informasi baik informasi akademis, kegiatan, maupun kebijakankebijakan yang disimpulkan dalam rapat komite dapat diakses dimana saja dan 
kapan saja oleh semua pihak yang berkepentingan, khususnya bagi siswa didik MTs Yasfi yang merupakan sasaran utama dari pengembangan sistem informasi ini.

Sistem Informasi Akademik adalah sistem yang meberikan pelayanan informasi yang berupa data dalam hal yang berhubungan dengan akademik. Dimana dalam hal ini pelayanan yan diberikan yaitu seperti: penyimpanan data untuk siswa baru, penentuan kelas, penetuan jadwal pelajaran, pembuatan jadwal mengajar, pembagian wali kelas dan proses penilaian.(Imelda \& Erik, 2014)

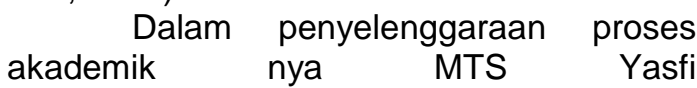
masingmenggunakan proses yang mengacu pada dokumen yang berupa berkas atau arsip dan belum memiliki penyimpanan basis data, sehingga sering terjadi penumpukan data siswa dan mengakibatkan sulitnya pencarian data siswa, dibutuhkan waktu lama untuk pembuatan laporan data siswa, pencatatan nilai akademik, dan keterbatasan waktu orang tua siwa sehingga informasi mengenai akademik tidak didapat dengan cepat.

Dengan adanya sistem informasi akademik diharapkan dapat mempermudah manajemen atau pengelola lembaga dalam menginformasikan skor dan nilai siswa, secara umum siswa atau wali siswa dapat memperoleh informasi lebih mudah, efisien, efektif dan mudah. (Lutfi, 2017). Selain sebagai sumber informasi, pembuatan website sekolah juga bertujuan untuk memperbaiki kesalahan-kesalahan dalam penyampaian informasi khususnya informasi mengenai sekolah. (Suhartanto, 2012)

\section{Metode Penelitian}

\subsection{Tehnik Pengumpulan Data}

Metode pengumpulan data yang penulis lakukan dalam penelitian ini adalah:

\section{a. Observasi}

Observasi adalah mengamati langsung terhadap kegiatan yang sedang terjadi, untuk mendapatkan data-data yang lengkap dan akurat. Pada metode observasi ini penulis melakukan pengamatan langsung pada MTS Yasfi untuk memperoleh gambaran operasional yang berlangsung di sekolah tersebut.

\section{b. Wawancara}

Wawancara dilakukan dengan berkomunikasi secara langsung, dan melakukan tanya jawab kepada kepala sekolah MTS Yasfi dan Tenaga Administrasi Sekolah (Tata Usaha), guna memperoleh informasi yang lengkap.

\section{c. Studi Pustaka}

Metode ini membantu penulis dalam hal membuat laporan yang ditunjang dengan buku-buku, jurnal, internet dan referensi yang berhubungan dengan masalah yang dimuat.

\subsection{Metode Pengembangan Perangkat Lunak}

Metode Pengembangan Perangkat Lunak Pada penelitian ini menggunakan metode pengembangan perangkat lunak model SDLC air terjun (waterfall) sering juga disebut model sekuensial linier (sequential linier) atau alur hidup klasik (classic life cycle). Model air terjun menyediakan pendekatan alur hidup perangkat lunak secara sekuensial atau terurut dimulai dari analisis, desain, pengodean, pengujian dan tahap pendukung (support). (Sukamto \& Shalahudin, 2014):

a. Analisis kebutuhan perangkat lunak Proses pengumpulan kebutuhan dilakukan secara intensif untuk menspesifikasikan kebutuhan perangkat lunak agar dapat dipahami perangkat lunak seperti apa yang dibutuhkan oleh user. Spesifikasi kebutuhan perangkat lunak pada tahap ini perlu didokumentasikan.

b. Desain

Desain perangkat lunak proses multi langkah yang fokus pada desain pembuatan program perangkat lunak termasuk struktur data, arsitektur perangkat lunak, representasi antar muka dan prosedur pengkodean. Tahap ini mentranslasi kebutuhan perangkat lunak dari tahap analisis kebutuhan ke representasi desain agar dapat diimplementasikan menjadi program pada tahap selanjutnya. Desain perangkat lunak yang dihasilkan pada tahap ini juga perlu didokumentasikan.

c. Pembuatan kode program

Desain harus ditranslasikan ke dalam program perangkat lunak. Hasil dari tahap ini adalah program komputer sesuai dengan desain yang telah dibuat pada tahap desain. 
d. Pengujian

Pengujian fokus pada perangkat lunak secara dari segi lojik dan fungsional dan memastikan bahwa semua bagian sudah diuji. Hal ini dilakukan untuk meminimalisir kesalahan (error) dan memastikan keluaran yang dihasilkan sesuai yang diinginkan.

e. Pendukung (support) atau pemeliharaan (maintenance)

Tidak menutup kemungkinan sebuah perangkat lunak mengalami perubahan ketika sudah dikirimkan ke user. Perubahan bisa terjadi karena adanya kesalahan yang muncul dan tidak terdeteksi saat pengujian atau perangkat lunak harus beradaptasi dengan lingkungan baru. Tahap pendukung atau pemeliharaan dapat mengulangi proses pengembangan mulai dari analis spesifikasi untuk perubahan perangkat lunak yang sudah ada, tapi tidak untuk membuat perangkat lunak baru. Tahap ini bisa dikatakan final dalam pembuatan suatu aplikasi atau sistem. Setelah melakukan analisis, desain maka sistem ini akan digunakan oleh pengguna. Kemudian aplikasi yang telah dibuat harus dilakukan pemeliharaan.

\subsection{PHP dan Mysql}

PHP adalah bahasa yang dirancang secara khusus untuk penggunaan pada web. PHP adalah tool untuk membuat halaman web dinamis. Pada awalanya PHP merupakan kependekan dari Personal Home Page (Situs personal). PHP pertama kali dibuat oleh Rasmus Lerdorf pad atahun 1995. Pada waktu itu PHP masih bernama FI (Form Interpreted), yang wujudnya berupa sekumpulan script yang digunakan untuk mengolah data dari web. Saat ini PHP adalah singkatan dari PHP:Hypertext Preprocessor, sebuah kepanjangan rekursif, yakni permainan kata dimana kepanjangannya terdiri dari singkatan itu sendiri: PHP:Hypertext Preprocessor. (Sianipar, 2015)

Mysql adalah salah satu aplikasi DBMS (Database Management System) yang sudah sangat banyak digunakan oleh para program aplikasi web. Dalam system database tak relasional, semua informasi disimpan pada satu bidang luas yang kadang kala data didalamnya sangat sulit dan melelahkan untuk diakses. Tetapi Mysql merupakan sebuah system database relasional, sehingga dapat mengelompokan informasi kedalam tabel-tabel atau grupgrup informasi yang berkaitan. Setiap tabel memuat bidang-bidang yang terpisah, yang mempresentasikan setiap bit informasi. Mysql menggunakan indeks untuk mempercepat proses pencarian terhadap baris informasi tertentu. Mysql memerlukan sedikitnya satu indeks pada tiap tabel. Biasanya akan menggunakan suatu Primary Keyatau pengenal unik untuk membantu penjejakan data. (Sianipar, 2015)

\section{Hasil dan Pembahasan}

\subsection{Sejarah Perusahaan/Institusi}

Salah satu lembaga pendidikan dibawah naungan Yayasan Pendidikan Fisabilillah adalah Madrasah Tsanawiyah (MTs). Madrasah Tsanawiyah berdiri pada tahun 1987 dan langsung menyelenggarakan pendidikan untuk tahun pelajaran 1987/1988 setelah mendapat izin operasional dari Kepala Kantor Wilayah Departemen Agama Propinsi Jawa Barat No : 412.5/1567/KESRA/1988.

Struktur Organisasi MTs Yasfi:

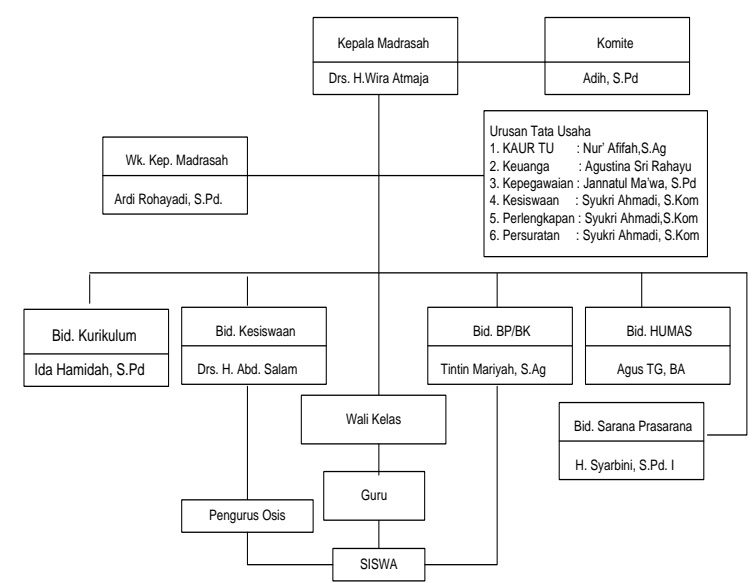

Sumber: Madrasah Tsanawiyah Yayasan Fisabillilah.

\subsection{Prosedur Sistem Usulan}

Adapun sistem usulan pada penelitian ini sebagai berikut:

1. Pengolahan Data Siswa

Proses pengolahan data siswa dilakukan oleh seorang administrator. Calon siswa yang telah mengisi formulir pendaftaran akan di input datanya berdasarkan formulir yang telah diserahkan oleh calon siswa baru. Penginputan data dilakukan diruang administrator pada link Moderasi Siswa 
dan secara otomatis data yang telah di input akan masuk kedalam database $m t s \_d b$ dengan nama table Siswa.

2. Pengolahan Data Guru

Sama hal nya seperti pengolahan data siswa, pengolahan data guru dilakukan oleh seorang administrator, calon guru yang akan direkrut mengisi sebuah formulir perekrutan, kemudian administrator akan meng input data guru berdasarkan formulir yang sudah di isi oleh calon guru pada link Moderasi Guru , penyimpanan otomatis ke dalam database mts_db pada table Guru.

3. Pengolahan Data Absen

Pengolahan data absen dilakukan oleh setiap guru mata pelajaran, guru yang sudah melakukan login akan masuk kedalam ruang guru dimana dalam ruang guru tersebut telah disediakan content - content yang memungkinkan guru untuk melakukan semua kegiatan dalam proses penginputan, salah satu nya menginput data absen yang dilakukan berdasarkan kelas yang guru tersebut ajarkan.

4. Pengolahan Data Nilai

Proses penginputan data nilai dilakukan oleh setiap guru, guru yang sudah login akan masuk kedalam ruang guru dimana di ruang guru tersebut telah disediakan content untuk peng input an data nilai, yaitu input nilai UTS, input nilai UAS dan input nilai kepribadian, kemudian secara otomatis wali kelas dapat memperoleh data nilai - nilai tersebut sesuai kelasnya. Data nilai yang sudah di input akan tersimpan otomatis kedalam database $m t s \_d b$ pada table nilai dan table nilai_kepribadian

\subsection{Desain Sistem (UML)}

Unified Modeling Language (UML) adalah bahasa Spesifikasi standard untuk mendokumentasikan, menspesifikasikan dan membangun system perangkat lunak.

\subsubsection{Use Case}

1. Login

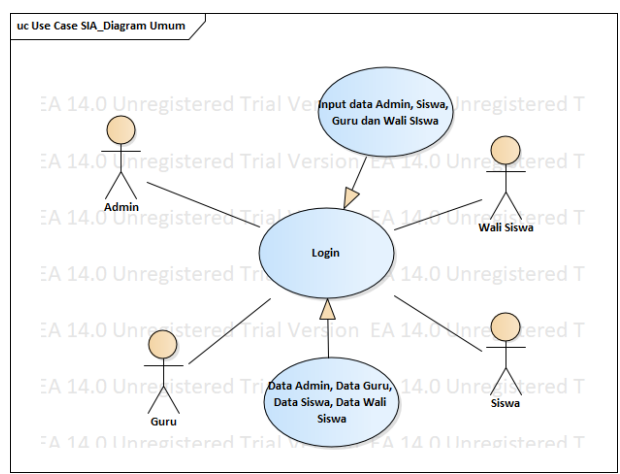

2. Input Nilai

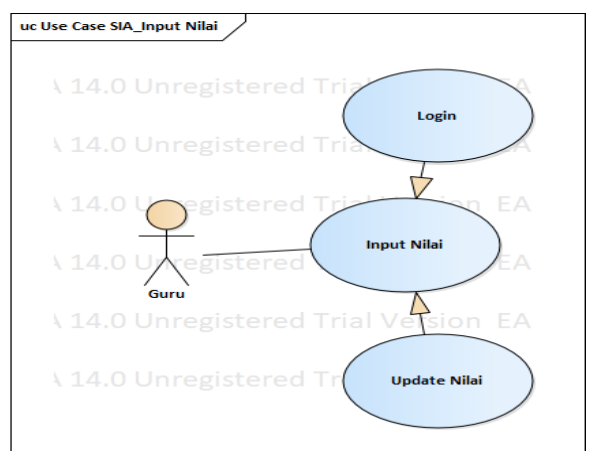

3. Wali Siswa

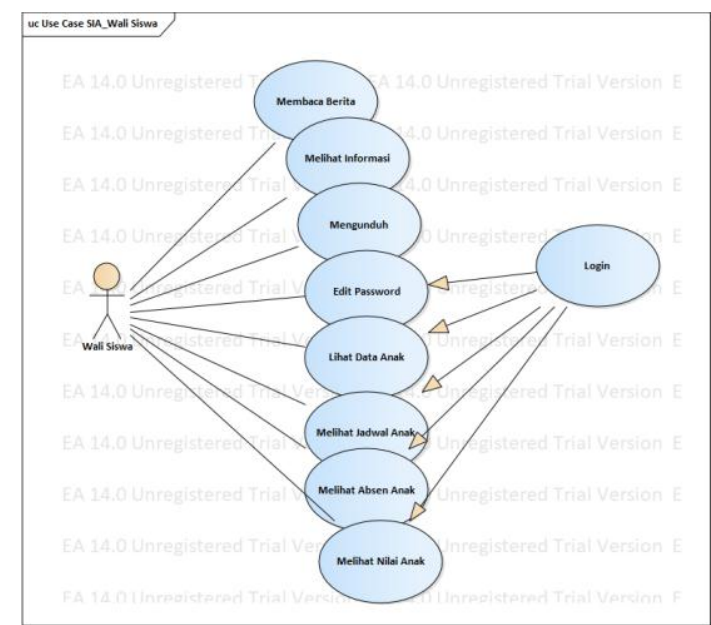

Sumber : Penelitian 2018 
3.3.2. Activity Diagram

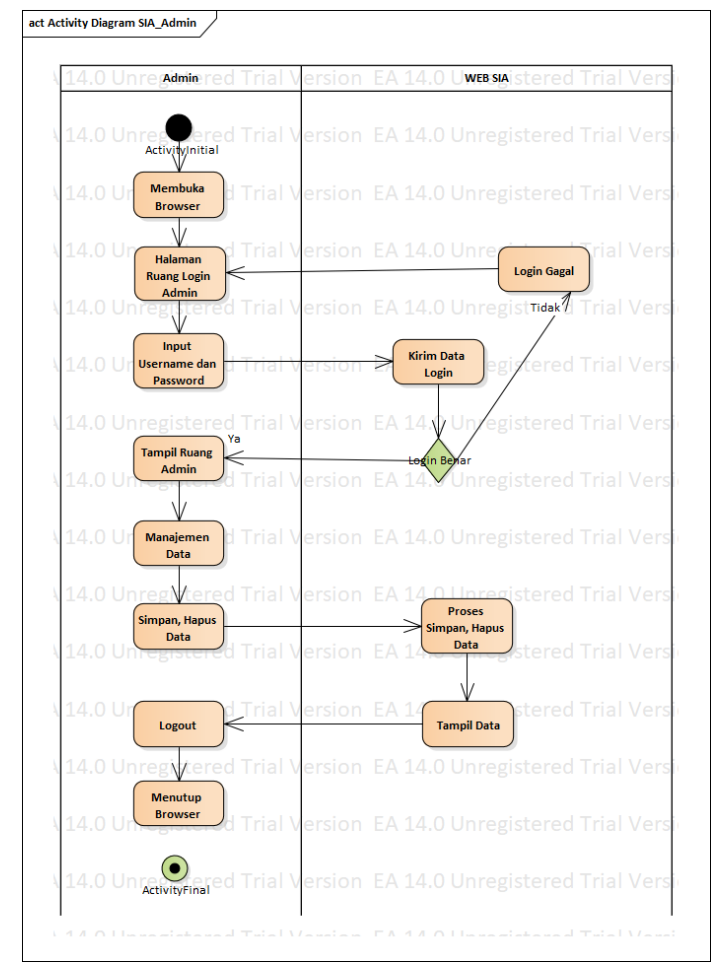

Sumber: Penelitian 2018

\subsubsection{Tampilan Web}

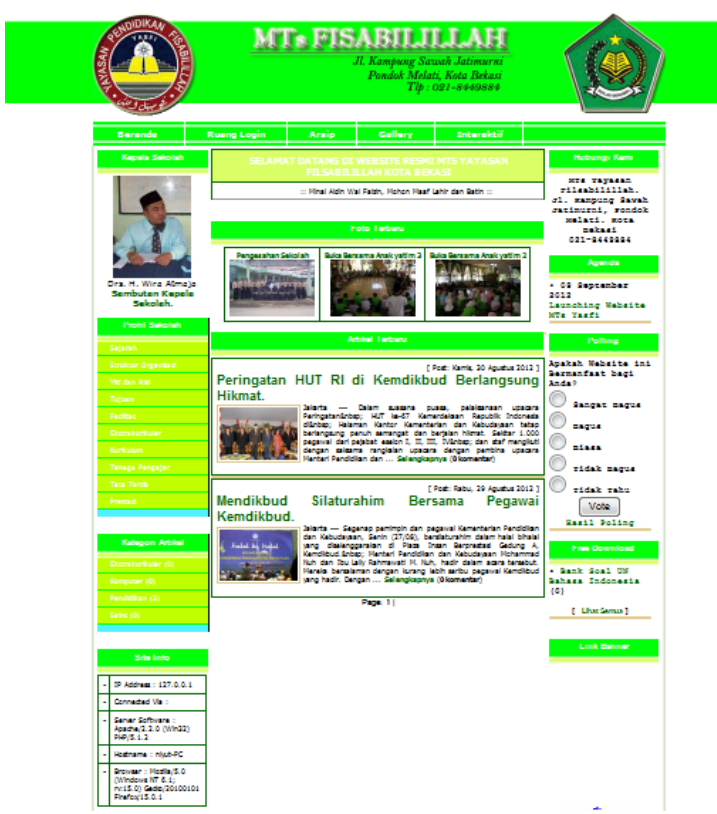

Gambar 3.1

Halaman Homepage

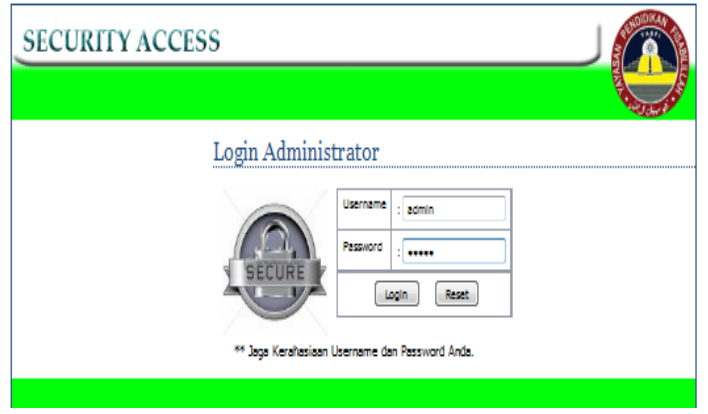

Gambar 3.2

Halaman Login

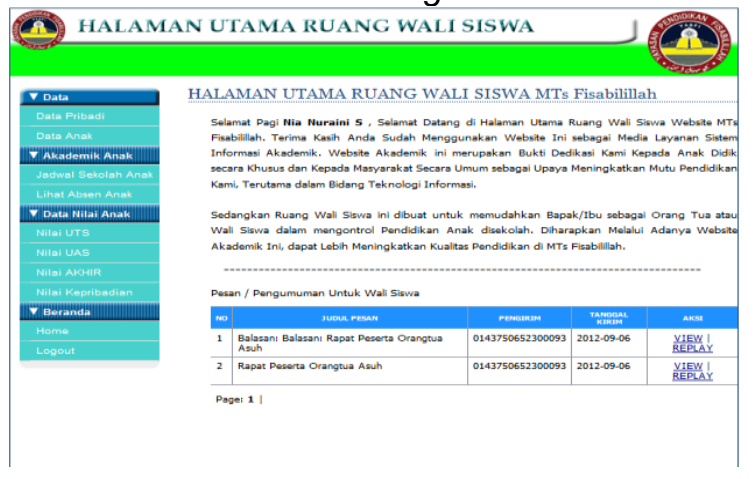

Gambar 3.3

Halaman Ruang Wali Siswa

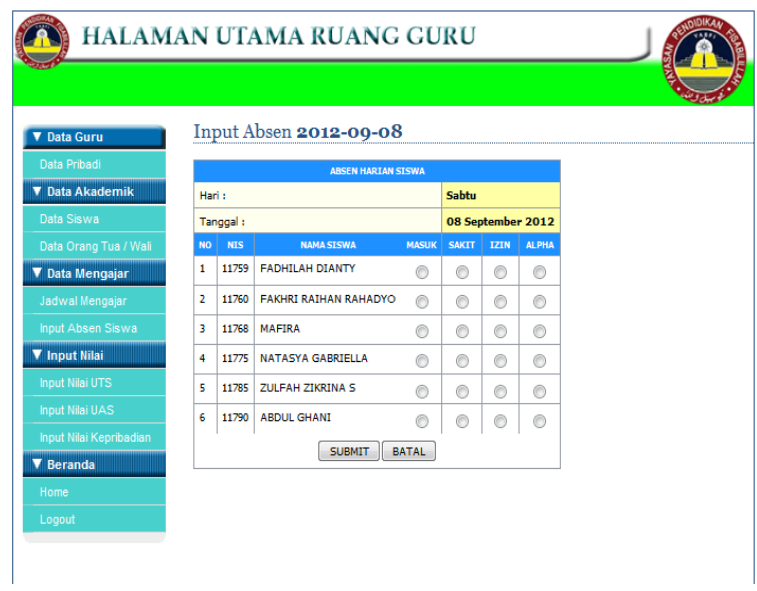

Gambar 3.4

Halaman Input Absen di Halaman Utama Ruang Guru 


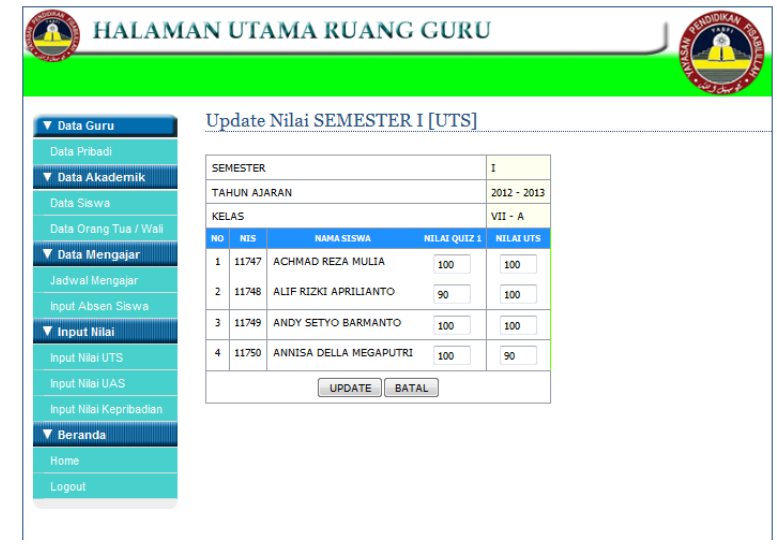

Gambar 3.5

Halaman Input Nilai di Halaman Utama Ruang Guru
4(1), 1-8. Retrieved from http://speed.web.id/ejournal/index.php/ Speed/article/view/226

Sukamto, R. A., \& Shalahudin, M. (2014). Rekayasa Perangkat Lunak Terstruktur dan Berorientasi Objek. Bandung: Informatika.

\section{Kesimpulan}

Implementasi sistem informasi berbasis website sangat membantu pihak-pihak yang tidak memiliki banyak waktu untuk hadir kesekolah sehingga dapat mengetahui informasi seputar kegiatan disekolah secara umum, Setelah sistem informasi di implementasi, kegiatan pengolahan data secara manual, sudah dapat dilakukan secara online tanpa harus berada disekolah. MYSQL sebagai server database untuk aplikasi PHP. Kemudahannya dalam integrasi ke berbagai aplikasi web (terutama PHP) cukup membantu dalam pengembangan sistem Informasi akademik sekolah ini.

\section{Referensi}

Imelda, \& Erik, M. (2014). Perancangan Sistem Informasi Akademik Pada Sekolah Dasar Negeri Sukajadi 9 Bandung. Jurnal Sistem Informasi Akademik, 3, 47-48.

Lutfi, A. (2017). Sistem Informasi Akademik Madrasah Aliyah Salafiyah Syafi' Iyah Menggunakan Php Dan Mysql Academic Information System of Salafiyah Syaf ' Iyah Senior Hight, 3(2), 104-112.

Sianipar, R. (2015). Membangun Web PHP dan MySQL. Bandung: Informatika.

Suhartanto, M. (2012). Pembuatan Website Sekolah Menengah Pertama Negeri 3 Delanggu Dengan Menggunakan Php Dan Mysql. Journal Speed - Sentra Penelitian Engineering Dan Edukasi, 